\title{
How to overcome NHS to private conversion apprehensions
}

\author{
Jayne Gibson, ${ }^{1}$ Practice Plan Regional Support Manager (RSM), explains \\ how Practice Plan can help dentists overcome any apprehensions they \\ may have about going private.
}

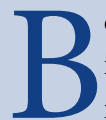
eing nervous about making the move is a natural response - after all, it is a big decision that needs a lot of consideration. This said, in my experience, there are a number of common reasons why NHS dentists feel apprehensive about making this move. However, with the right support, they can all be overcome.

\section{Patient retention}

'If I decide to make the move, will patients want to come with me and how many will I need to retain a viable and thriving business?' This is a completely normal thought for an NHS dentist to have when considering moving to private, and it's a question I have been asked many times over the years.

Very often, the short answer is that you don't need as many patients as you may think. Many dentists have said that delivering to NHS targets can mean working on a treadmill of seeing patient after patient. One of the benefits of offering private care is the removal of external targets and being able to set your own. The upshot is that you see fewer patients and spend more time with them whilst generating the same income.

'That's a lot more difficult than it sounds...' you may think, but this is exactly why we have proven systems in place that crunch all the numbers to work out exactly how many patients you will need in order to replace your NHS contract, and our processes have been used to help hundreds of dentists successfully move to private practice.

Alongside this, the current landscape in private dentistry is very much in your favour. Because NHS waiting times are continuing to

'Jayne has been a Regional Support Manager at Practice Plan for 13 years and has 17 years' experience in the dental industry. Practice Plan is the UK's leading provider of practice-branded patient membership plans, partnering with over 1,500 dental practices, and offering a wide range of business support services. grow, more and more people are seeking out private dentistry, and the demand is higher than it has been for many years.

\section{Communicating the change}

Many dentists I have worked with over the years have initially been apprehensive about how to tell their patients about the change, and what their staff may think about going private.

To help with this, I, like my other RSM colleagues, will sit with the dentist when they have that initial conversation with their staff, and I advise them on how to explain the reasons for making the move and what benefits it will deliver to the practice and its patients.

We also use our years of experience to put together the correct pricing structure, before providing training for the whole practice team, which gives them confidence in how to explain the reasons, costs and benefits of the move to patients.

\section{Income security}

This is one of the main reasons a lot of NHS dentists are reluctant to make the move to private because of the security they feel they have within the NHS.

Despite the evidence that life in private dentistry can be more rewarding, many dentists are worried about letting go of their regular NHS income.

This is where the introduction of a patient plan comes in. Moving all your patients onto a monthly plan provides you with an alternative regular income to your NHS contract.

To help you successfully set up your plan, we go through what is called an income replacement calculator. This is a tried-andtrusted tool that looks at all aspects of your practice, to show you how many patients you will need in order to replace your NHS income.

And, as I have mentioned, I find that dentists feel less apprehensive about this financial security once they realise that the

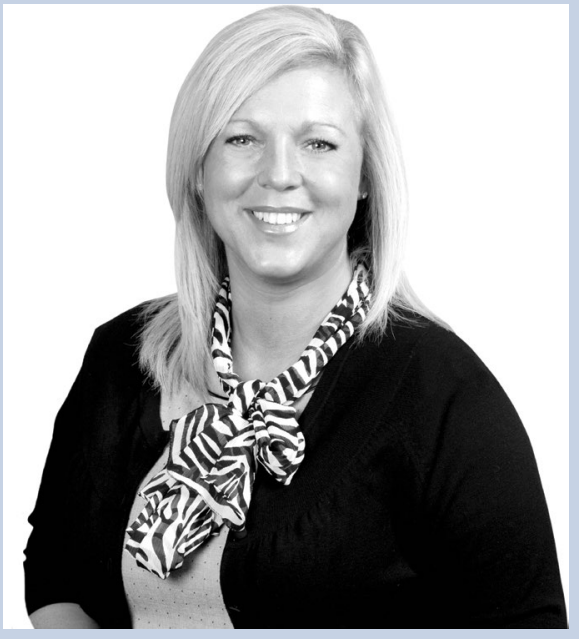

Jayne Gibson

number of patients they need to see in order to earn the same level of income is a lot lower than they first thought.

\section{I am on my own}

A lot of dentists tend to feel like they are isolated and alone when it comes to moving to private practice. However, you are not on your own as we are here to support you every step of the way.

Many others have made this journey, and I find being able to connect dentists who are considering going private with those who have already successfully left the NHS helps to give them a clear picture of what life could be like for them.

\section{'Jayne, I wish I had done it sooner'} Those are the reasons why some dentists are still nervous about making the move, however, in our experience, dentists who have gone private feel happier, more in control and are more fulfilled in their professional lives.

And one thing I have heard many, many times from those that have moved to private is, 'Jayne, I wish I had done it sooner'. 